\title{
Invasive procedures carried out in conscious children: contrast between North American and European paediatric oncology centres
}

\author{
R D W Hain, C Campbell
}

\begin{abstract}
Aim-To define practice in managing repeated invasive procedures in selected paediatric oncology centres in North America and Europe, especially the United Kingdom; to define and contrast concerns that shape policy making, and to contrast practice, particularly regarding procedures performed on conscious patients.

Methods-Postal survey: 118 centres of the Pediatric Oncology Group and the United Kingdom Children's Cancer Study Group received questionnaires.

Results-68 questionnaires (58\%) were returned (52 from North America, 12 from Europe). For all procedures, North American centres tended to use less effective techniques than European, especially for bone marrow procedures. Many North American centres reported performing these on conscious patients on at least three quarters $(25 \%)$ or half $(30 \%)$ the occasions. In contrast, corresponding figures for the European centres were $6 \%$ and $0 \%$.

Conclusions-Many bone marrow procedures are still carried out in the conscious patient despite the safety and effectiveness of modern anaesthetic and deep sedation techniques. There appears to be a greater reluctance to offer these to patients in North American centres than in European ones. This may reflect a misperception that the risks of adverse effects are high. Several non-pharmacological techniques are used, but they remain uncommon. (Arch Dis Child 2001;85:12-15)
\end{abstract}

Keywords: paediatric oncology; pain relief; invasive investigation procedures

In the management of distress associated with the diagnostic and therapeutic interventions required by paediatric cancer management, the range of options available is becoming wider. At the same time, in children as in adults there has been a shift in attitudes towards pain. It is increasingly recognised that a child's experience of pain is at least as intense as that of an adult, ${ }^{12}$ and it is becoming culturally less acceptable to allow children to "tolerate pain well."

It is also recognised that anxiety and previous experiences of pain are significant influences in the distress of repeated invasive procedures. ${ }^{4-6}$ In order to minimise both pain and anxiety, various approaches have evolved. Techniques vary from those that simply teach the child to cope with pain, ${ }^{7}$ through those that modify the experience of physical pain or anxiety, ${ }^{8-10}$ to those that result in unconsciousness. ${ }^{10-13}$ This postal survey defines and contrasts the approaches taken in paediatric oncology centres in Europe and North America.

\section{Methods}

Questionnaires were sent to all units in the Pediatric Oncology Group (POG) and the United Kingdom Children's Cancer Study Group (UKCCSG). One hundred and eighteen questionnaires were received (96 centres in POG, 22 in UKCCSG). These included three centres in Europe that were not in the United Kingdom, two of which were members of UKCCSG and one of POG. The first questionnaire was followed after two weeks by a reminder and the offer of a second.

The questionnaire was in three sections. The first offered eight concerns that might influence the policy of a unit in managing painful oncological procedures and asked the respondent to choose and rank the five most important. Respondents were asked to add any concerns that were not on the list and rank them accordingly.

The second section offered seven procedures and six approaches to their management. For each procedure, respondents were invited to estimate the proportion of times each management approach was used. The alternatives offered were $0 \%, 25 \%, 50 \%, 75 \%$, or $100 \%$ of the time. The options were listed in random order to avoid the automatic association of increasing invasiveness of the procedures with degree of intervention in the management.

In the third section respondents were invited to list any approaches that were not mentioned elsewhere on the questionnaire. A final question invited any further comments.

\section{Results}

Sixty eight questionnaires were returned (response rate $58 \%$ ). Of these, 52 were from North America (46 from the USA, six from Canada) and 16 from Europe (14 from United Kingdom, one from each from the Irish Republic and the Netherlands). Results are shown in tables 1 and 2, and in figs 1 and 2 .

In addition to the alternatives given in the questionnaire, nine North American centres reported the use of an opioid and anxiolytic combination. Of these, five referred to it as "conscious sedation" and four others appended it to their answers to question 3 (local anaesthetic/anxiolytic). These responses were excluded from analysis. 
Table 1 Main concerns that influence unit policy in management of painful procedures

\begin{tabular}{|c|c|c|c|c|c|c|}
\hline \multirow[b]{2}{*}{ Concern } & \multicolumn{6}{|c|}{ Ranking } \\
\hline & $1 s t$ & 2nd & $3 r d$ & $4 t h$ & 5 th & Total \\
\hline \multicolumn{7}{|l|}{ North American respondents $(n=51)$} \\
\hline Degree of patient discomfort from procedure & 36 & 0 & 5 & 1 & 1 & 50 \\
\hline Risk of adverse effects (unit experience) & 8 & 7 & 14 & 5 & 2 & 36 \\
\hline Risk of adverse effects (published) & 4 & 7 & 6 & 10 & 2 & 29 \\
\hline Availability of staff & 3 & 3 & 9 & 10 & 13 & 38 \\
\hline Degree of patient discomfort from management & 3 & 16 & 6 & 7 & 5 & 37 \\
\hline Other & 0 & 2 & 0 & 1 & 0 & 3 \\
\hline \multicolumn{7}{|c|}{$\begin{array}{l}\text { - Ability to do procedure lying still (ranked 2nd) } \\
\text { - Patient's age, ability to use non-pharmacological methods (ranked 2nd) } \\
\text { - Parental coping (ranked 4th) }\end{array}$} \\
\hline Availability of facilities & 0 & 4 & 4 & 7 & 11 & 26 \\
\hline Cost & 0 & 1 & 3 & 4 & 6 & 14 \\
\hline Risk of litigation & 0 & 0 & 1 & 1 & 0 & 2 \\
\hline \multicolumn{7}{|l|}{ European respondents $(n=16)$} \\
\hline Degree of patient discomfort from procedure & 14 & 1 & 0 & 0 & 0 & 15 \\
\hline Degree of patient discomfort from management & 2 & 9 & 0 & 0 & 3 & 14 \\
\hline Availability of facilities & 0 & 0 & 3 & 4 & 6 & 13 \\
\hline Availability of staff & 0 & 0 & 4 & 6 & 2 & 12 \\
\hline Risk of adverse effects (unit experience) & 0 & 4 & 7 & 0 & 0 & 11 \\
\hline Risk of adverse effects (published) & 0 & 1 & 2 & 5 & 2 & 10 \\
\hline Cost & 0 & 1 & 0 & 1 & 1 & 3 \\
\hline Risk of litigation & 0 & 0 & 0 & 0 & 1 & 1 \\
\hline Other & 0 & 0 & 0 & 0 & 0 & 0 \\
\hline
\end{tabular}

Concerns are listed in order, according to number of times each was ranked the most important.

Table 2 Non-pharmacological adjuncts to sedation for painful procedures in paediatric oncology

\begin{tabular}{ll}
\hline Technique & No of centres \\
\hline Distraction/play & 7 \\
Imagery/visualisation & 5 \\
Relaxation techniques & 3 \\
Hypnosis & 3 \\
Breathing exercises & 3 \\
Music & 1 \\
"Numby machine" & 1 \\
\hline
\end{tabular}

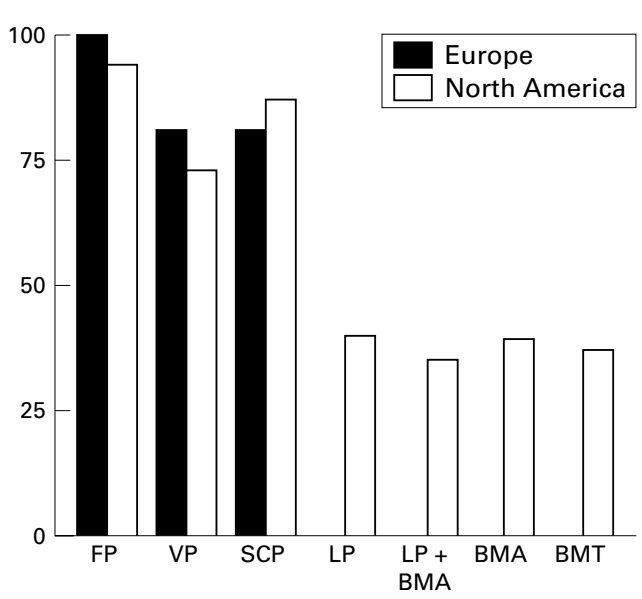

Figure 1 Proportion of paediatric oncology centres (\%) which reported using either topical analgesic cream alone or no medication at all for procedures on at least three quarters of occasions. BMA, bone marrow aspirate; BMT, bone marrow trephine or biopsy; FP, finger prick; LP, lumbar puncture; SCP, subcutaneous port; VP, venepuncture.

\section{Discussion}

The overall response rate of $58 \%$ is disappointing, though not untypical of postal surveys. While it complicates interpretation of the statistical data, some observations can be made.

There appears to be a striking difference between the North American and European approaches to management of painful procedures in paediatric oncology. A much larger proportion of responding centres in North America reported still performing invasive bone marrow procedures (that is, bone marrow

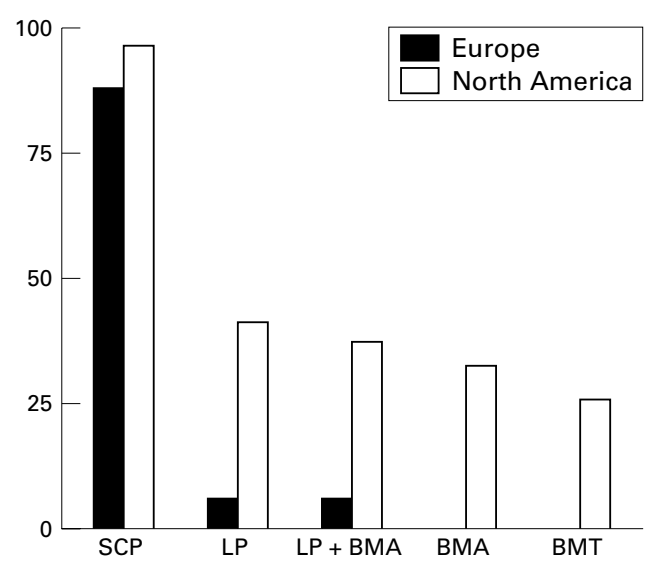

Figure 2 Proportion of paediatric oncology centres which reported carrying out procedures in the conscious child on at least half the occasions. BMA, bone marrow aspirate; BMT, bone marrow trephine or biopsy; FP, finger prick; LP, lumbar puncture; SCP, subcutaneous port; VP, venepuncture.

aspirate or bone marrow trephine) on conscious children. Nearly one third of North American centres used neither general anaesthetic nor deep sedation for the majority of bone marrow procedures (fig 2). A significant minority of North American centres considered a local anaesthetic and anxiolytic combination, often with non-pharmacological distraction techniques (table 2), to be sufficient, while only one centre in Europe did so. Over a quarter of North American centres, but no European ones, reported using nothing or topical anaesthetic alone (fig 1).

A move away from performing bone marrow procedures on conscious patients has long been anticipated ${ }^{14-16}$ but appears to be happening only slowly. There is still reluctance in North America to use combinations of drugs that reliably result in unconsciousness, even for bone marrow procedures.

The reason for this reluctance is unclear. The ranking of concerns in North American and European centres (table 1) was very similar. However, North American centres were 
more likely than European ones to rank the risk of adverse effects as their most important concern. In fact, research suggests that repeated general anaesthetic or deep sedation are very safe. ${ }^{4}{ }^{12}{ }^{17-19}$ Repeated pain and anxiety in childhood carry significant morbidity, ${ }^{20-22}$ and procedures that are considered minor by physicians can nevertheless cause great pain and anxiety to children. ${ }^{23}{ }^{24}$ Withholding general anaesthesia from children perhaps allows a priority of physicians' perceptions over the needs of the child.

Many centres reported that procedures were performed on conscious children because of practical difficulties in obtaining anaesthetic support. In patients undergoing "conscious sedation", ${ }^{25}$ airway reflexes are preserved so the presence of an anaesthetist may be unnecessary. Responding centres in this study used the term inconsistently. Techniques described as conscious sedation included midazolam, benzodiazepines in combination with opioids, and ketamine or propofol.

The risk of respiratory depression with benzodiazepines ${ }^{26-28}$ means they are probably too toxic for procedures that are very minor, alone or in combination with an opioid. Furthermore, they do not induce complete analgesia or unconsciousness during bone marrow procedures..$^{10}$ In the absence of an anaesthetist, therefore, such a mixture combines inadequate analgesia and sedation with an unacceptable risk of adverse effects. A small number of respondents reported that they considered even the risk of midazolam alone to be such that it needed to be given by an anaesthetist.

Ketamine or propofol usually result in unconsciousness. Some respondents pointed out that use of the term "conscious sedation" to describe this approach, though widespread, is misleading. The term "deep sedation" is more appropriate if a distinction from general anaesthesia is to be made, but both need to be given by an anaesthetist and therefore impose the same logistical constraints on busy paediatric oncology units.

\section{CONCLUSIONS}

Despite the safety and effectiveness of modern anaesthetic techniques, many bone marrow procedures are still carried out in the conscious patient. There appears to be a greater reluctance to offer general anaesthesia to patients in the North American centres surveyed than in the European ones. The explanation for this may be a misperception that the risks of adverse effects are high, or be related to practical difficulties in obtaining anaesthetic support. With the advent of newer techniques, the opioid/anxiolytic combination has little to recommend it. Various alternative and complementary non-pharmacological techniques are used, but they remain relatively uncommon.

1 Schechter NL. The undertreatment of pain in children: an overview. Pediatr Clin North Am 1989;36:781-94.

2 Anand KJS, Carr D. The neuroanatomy neurophysiology and neurochemistry of pain stress and analgesia in newborns and children. Pediatr Clin North Am 1989;36:
3 Swafford A. Pain relief in the pediatric patient. Med Clin North Am 1968;52:131-6.

4 Hain WR, Tomlinson JH, Barbor PR. Anaesthesia for minor procedures in children with malignant disease. $\mathcal{F} R$ Soc Med 1985;78:715-20.

5 Harris CV, Bradlyn AS, Ritchey AK, et al. Individual differences in pediatric cancer patients $=$ reactions to invasive medical procedures: a repeated measures analysis [see comments]. Pediatr Hematol Oncol 1994;11:293-9.

6 Mansson ME, Bjorkhem G, Wiebe T. The effect of preparation for lumbar puncture on children undergoing chemotherapy. Oncol Nursing Forum 1993;20:39-45.

7 Blount RL, Powers SW, Cotter MW, et al. Making the system work. Training pediatric oncology patients to cope and their parents to coach them during BMA/LP procedures. Behav Modif 1994;18:6-31.

8 Juarez GJ, Oliveras M, Hidalgo E, et al. Anesthetic efficacy of eutectic prilocaine-lidocaine cream in pediatric oncology patients undergoing lumbar puncture. Ann Pharmacother patients underg

9 Calamandrei M, Messeri A, Busoni P, et al. Comparison of two application techniques of EMLA and pain assessment in pediatric oncology patients. Reg Anesth 1996;21:557-60.

10 Marx CM, Stein J, Tyler MK, et al. Ketamine-midazolam versus meperidine-midazolam for painful procedures in pediatric oncology patients. F Clin Oncol 1997;15:94-102.

11 Scheiber G, Ribeiro FC, Karpienski H, et al. Deep sedation with propofol in preschool children undergoing radiation therapy. Paediatr Anaesth 1996;6:209-13.

12 McDowall RH, Scher CS, Barst SM. Total intravenous anesthesia for children undergoing brief diagnostic or therapeutic procedures. F Clin Anesth 1995;7:273-80.

13 Macpherson CF, Lundblad LA. Conscious sedation of pediatric oncology patients for painful procedures: development and implementation of a clinical practice protocol [review]. F Pediatr Oncol Nurs 1997;14:33-42.

14 Berde C, Ablin A, Glazer J, et al. American Academy of Pediatrics report of the subcommittee on disease-related Pediatrics report of the subcommittee on disease-relat
pain in childhood cancer. Pediatrics 1990;86:818-25.

15 Zeltzer LK, Altman A, Cohen D, et al. American Academy of Pediatrics report of the subcommittee on the manageof Pediatrics report of the subcommittee on the manage-
ment of pain associated with procedures in children with ment of pain associated with proced

16 Zeltzer LK, Jay SM, Fisher DM. The management of pain associated with pediatric procedures. Pediatr Clin North Am 1989;36:941-64

17 Wark H, O'Halloran M, Overton J. Prospective study of liver function in children following multiple halothane anaesthetics at short intervals. $\operatorname{Br} \mathcal{F}$ Anaesth 1986;58:1224-8.

18 Schwanda AE, Freyer DR, Sanfilippo DJ, et al. Brief unconscious sedation for painful pediatric oncology procedures. Intravenous methohexital with appropriate monitoring is safe and effective. Am f Pediatr Hematol Oncol 1993;15: 370-6.

19 Fisher DM, Robinson S, Brett CM, et al. Comparison of enflurane, halothane, and isoflurane for diagnostic and therapeutic procedures in children with malignancies. Anesthesiology 1985;63:647-50.

20 Anand KJS. Long-term effect of pain in neonates and infants. In: Jensen TS, Turner JA, Wiesenfeld-Hallin Z, infants. In: Jensen TS, Turner JA, Wresenfeld-Hallin Z, eds. Proceedings of the 8th

21 Fitzgerald M, Millard C, MacIntosh N. Hyperalgesia in premature infants. Lancet 1988;i:292.

22 Taddio A, Goldbach M, Ipp M, et al. Effect of neonatal circumcision on pain responses during vaccination in boys. Lancet 1995;345:291-2.

23 Kazak AE, Penati B, Waibel MK, et al. The Perception of Procedures Questionnaire: psychometric properties of a brief parent report measure of procedural distress. 7 Pediatr Psychol 1996;21:195-207.

24 Ljungman G, Kreuger A, Andreasson S, et al. Midazolam nasal spray reduces procedural anxiety in children. Pediatrics 2000;105:73-8.

25 American Academy of Pediatrics Committee on Drugs. Guidelines for the monitoring and management of pediatric patients during and after sedation for diagnostic and therapeutic procedures. Pediatrics 1992;89:1110-16.

26 Sandler ES, Weyman C, Conner K. Midazolam versus fentanyl as premedication for painful procedures in children with cancer. Pediatrics 1992;89:631-4.

27 Sievers TD, Yee JD, Foley ME, et al. Midazolam for conscious sedation during pediatric oncology procedures: safety and recovery parameters. Pediatrics $1991 ; \mathbf{8 8}: 1172-9$.

28 Yaster M, Nichols DG, Deshpande J. Midazolam-fentanyl intravenous sedation in children: case report of respiratory arrest. Pediatrics 1990;86:463-7.

\section{Commentary}

CONSCIOUS SEDATION OR GENERAL ANAESTHESIA

FOR INVASIVE MEDICAL PROCEDURES: WHICH IS

BETTER?

Management of pain, including pain resulting from invasive medical procedures, is increasingly recognised as a critical part of patient management. Paediatric oncology patients rate pain due to treatment and procedures as greater than pain due to disease. ${ }^{1}$ On average children with acute lymphoblastic leukaemia 
undergo approximately 10 lumbar punctures and four bone marrow aspirates during their course of treatment. In this paper, Hain and colleagues compare sedation techniques for bone marrow procedures in paediatric oncology centres in Europe and North America.

The data presented were collected from questionnaires. Limitations of this technique are well known, and include bias introduced by low response rates ( $58 \%$ in this study) as well as the validity of self reported behaviour. Recent data indicate that three techniquespatient vignettes, standardised patients, and chart abstraction - are relatively equivalent with respect to measuring quality. ${ }^{2}$ Although this study did not include any of these techniques, we believe that the results are probably accurate. In general, North American centres are more likely to perform bone marrow aspiration and biopsy using conscious sedation than European centres which use general anaesthesia.

Hain does not clearly define the term "conscious" or "conscious sedation". Pharmacological sedation including benzodiazepines, barbiturates, opioids, and other medications such as ketamine, nitrous oxide, and propofol, results in a continuum of consciousness. Different organisations have developed their own guidelines and definitions regarding levels of sedation and anaesthesia. The American Academy of Pediatrics (AAP) established guidelines in 1989, which were revised in $1992 .{ }^{3}$ Under "conscious sedation" protective airway reflexes are maintained, the patient can maintain his or her own airway, and can respond to verbal stimuli. "Deep sedation" is a medically controlled state of depressed consciousness or unconsciousness from which the patient is not easily aroused. It may be accompanied by a partial or complete loss of protective reflexes, and includes the inability to maintain a patent airway independently and respond purposefully to physical stimulation or verbal command. General anaesthesia denotes a state of unconsciousness with complete loss of airway protective reflexes, independent airway control, and response to stimuli. The AAP recommends that appropriate personnel be present depending on the level of sedation used.

In contrast, committees in the United Kingdom define two levels of sedation. ${ }^{4}$ There is no distinction between deep sedation and general anaesthesia and the presence of an anaesthesiologist is required for both procedures. Despite these guidelines, as Hain states, the term "conscious sedation" is often used inconsistently. Many providers use anxiolytic/opioid combinations to achieve "conscious sedation" although there is often tremendous overlap between this level of sedation and "deep sedation". Children under "conscious sedation" may experience deep sedation with potential loss of airway control. Hain and colleagues' exclusion from the analysis of those clinics using conscious sedation, may have biased the results by ignoring effective techniques which are used to manage procedural pain.

We could find no studies that compare general anaesthesia to conscious sedation. How- ever, many studies document the efficacy of opioid/anxiolytic combinations in children for painful procedures including fracture reduction, lumbar puncture, bone marrow aspirate or biopsy, and dental procedures, in both the ambulatory and inpatient settings. Sievers and Tobias showed the safety and efficacy of drug combinations - such as, midazolam with either fentanyl or morphine or ketamine for procedure related pain in paediatric oncology patients. ${ }^{56}$ Parker et al reported 350 procedures including lumbar punctures, bone marrow aspirations or biopsies, radiotherapy sessions, or imaging studies, on 68 children using midazolam and ketamine for sedation. ${ }^{7}$ One hundred percent of patients experienced "effective sedation" as defined by parental and physician satisfaction and ability to perform the procedures. Conscious sedation, using various agents, can provide effective analgesia and has other benefits. It can be safely administered in various healthcare settings and scheduling the operating room and finding an available anaesthesiologist is unnecessary. In addition, in some countries, conscious sedation is far more cost effective than general anaesthesia.

Hain and colleagues imply that many children in North America undergo bone marrow procedures in the "conscious" state without adequate analgesia. We do not believe that this conclusion is either accurate or supported by their results. However, we do acknowledge that there are differences between North America and Europe in how adequate analgesia is provided for bone marrow related procedures.

The decision as to what type of anaesthesia is necessary for invasive medical procedures is complicated and depends upon many factors including the setting, types of anaesthesia and trained personnel available, cost, and patient preference. More work will be needed, however, to determine if general anaesthesia is superior to conscious sedation for specific invasive medical procedures.

S SPACE

S KHARASCH

H BAUCHNER

Department of Pediatrics, Boston University School of Medicine, Boston Medical Center, Boston, MA, USA

Correspondence to: Howard Bauchner (Hbauchne@ahrq.gov)

1 Ljungman G, Gordh T, Sorensen S, et al. Pain in paediatric oncology: interviews with children, adolescents, and their parents. Acta Paediatrica 1999;88:623-30.

2 Peabody JW, Luck J, Glassman P, et al. Comparison of vignettes, standardized patients, and chart abstraction. FAMA 2000;283:1715-22.

3 American Academy of Pediatrics, Committee on Drugs. Guidelines for the elective use of conscious sedation, deep sedation, and general anaesthesia in pediatric patients. Pediatrics 1992;89:1110-15.

4 Murphy MS. Sedation for invasive procedures in pediatrics. Arch Dis Child 1997;77:281-4.

5 Sievers TD, Yee JD, Foley PJ, et al. Midazolam for conscious sedation during pediatric oncology procedures: safety and recovery parameters. Pediatrics 1991;88:1172-9.

6 Tobias JD, Phipp S, Smith B, et al. Oral ketamine premedication to alleviate the distress of invasive procedures in pediatric oncology patients. Pediatrics 1992;90:537-41.

7 Parker RI, Mahan RAQ, Giugliano D, et al. Efficacy and safety of intravenous midazolam and ketamine as sedation for therapeutic in diagnostic procedures in children. Pediatrics 1997;99:427-31. 